\title{
Effect of Nitrogen Ion Implantation Energy on the Mechanical and Chemical Properties of AISI M50 Steel
}

\author{
Xiangyu Xie, ${ }^{1}$ Chao Chen, ${ }^{2}$ Jun Luo $\left(D,{ }^{1}\right.$ and Jin $X u^{2}$ \\ ${ }^{1}$ Guizhou Provincial College-based Engineering Research Center for Materials Protection of Wear and Corrosion, \\ College of Chemistry and Materials Engineering, Guiyang University, Guiyang 550005, China \\ ${ }^{2}$ School of Mechanical Engineering, Guizhou University, Guiyang 550000, China \\ Correspondence should be addressed to Jun Luo; luojun_gyu@sina.com
}

Received 10 June 2021; Revised 14 July 2021; Accepted 11 September 2021; Published 12 October 2021

Academic Editor: Valeria Di Sarli

Copyright (c) 2021 Xiangyu Xie et al. This is an open access article distributed under the Creative Commons Attribution License, which permits unrestricted use, distribution, and reproduction in any medium, provided the original work is properly cited.

\begin{abstract}
Nitrogen ion implantation has shown its role in enhancing steel surface properties. In this work, AISI M50 steel was implanted with nitrogen ions by using the metal vapor vacuum arc technique with a dose of $2 \times 10^{17} \mathrm{~cm}^{-2}$, and corresponding implanted energies were at $60 \mathrm{keV}, 80 \mathrm{keV}$, and $100 \mathrm{keV}$, respectively. The distribution of implanted nitrogen ions was calculated, and the samples were tribologically tested and examined. As shown by the results, the microhardness in implanted samples was 1.17 times greater relative to that of the unimplanted sample. The implantation of the nitrogen ion leads to a change in the friction coefficient of the AISI M50 steel. Adhesive wear mechanism occurs in the unimplanted sample, and adhesion resistance tends to increase when nitrogen-implanted energy increases. The formation of oxides $\alpha-\mathrm{Fe}_{2} \mathrm{O}_{3}$ and $\mathrm{Fe}_{3} \mathrm{O}_{4}$ further enhanced the tribological properties for implanted samples.
\end{abstract}

\section{Introduction}

Bearing, as an integral part in various mechanical equipment, is critical for equipment performance, level, quality, and reliability of the equipment [1]. Advance of science and technology has stimulated greater demands for bearing materials, which possess reinforced performance and applicability to harsh environments [2]. As a representative metal material marked by favorable mechanical properties, AISI M50 steel has been extensively adopted by the production for aerobearings [3]. AISI M50 steel is often subjected to continuous heavy loads and high speeds, and in these harsh environments, the material surface can undergo a variety of failure behaviours, such as damage, wear, and plastic deformation [4]. In order to reinforce the surface properties and wear resistance for the steel, many surface treatment methods have been proposed. It is a feasible choice to use surface modification technology for the improvement of steel surface properties. Compared to other surface techniques, such as chemical heat treatment [5], laser melting [6], and chemical etching [7], ion implantation possesses higher precision and a cleaner environment [8]. Ion implantation can easily create a progressive interface between the implanted surface layer and the unaffected material volume, without altering the dimension of original materials. Ion implantation technique triggers variations in the material surface and chemical composition, including microstructure [9], chemical properties [10], and biological properties [11].

According to former studies, the implantation of nitrogen ions and other kinds of ions into specific steels can improve mechanical and tribological properties, especially hardness, and this has a connection with wear resistance [12-15]. Moreover, ion implantation is used for different metallic materials and acts beneficially for preventing from another unique form of damage likewise cavitation erosion $[16,17]$. So far, few studies concentrate on the surface modifications in AISI M50 steel with ion implantation, in particular nitrogen ion implantation. Multiple factors may exert influence on the treated surface's ultimate quality, including the implanted energy, type of ions, and doses $[18,19]$. However, much attention 
has been paid to the assessment about AISI M50 steel surface properties under various implantation conditions, especially the implanted energy. The research implanted nitrogen ions containing various energies into the AISI M50 steel surface and reported the improvement in surface properties, thus providing valuable references for industrial applications.

\section{Materials and Methods}

2.1. Experimental Sample. AISI M50 steel was used as a metal substrate in the formation of form C: $0.82 \mathrm{wt} . \%, \mathrm{Cr}$ : 4.00 wt.\%, Mo: 4.25 wt.\%, V: 1.10 wt.\%, Mn: 0.16 wt.\%, Si: 0.13 wt.\%, and Ni: 0.07 wt.\%, balanced with Fe. Prior to nitrogen ion implantation, AISI M50 steel was cut into flat samples with a dimension of $30 \mathrm{~mm} \times 20 \mathrm{~mm} \times 10 \mathrm{~mm}$ and then polished by silicon carbide emery papers of 120,400 , 800 , and 1200 grit. The last polishing was made with $3.5 \mu \mathrm{m}$ and $1 \mu \mathrm{m}$ diamond pastes to a mirror finish with a roughness of $R a$ approx. $0.05 \mu \mathrm{m}$. All samples were cleaned ultrasonically with acetone and dried.

2.2. Ion Implantation Method. The implantation samples were implanted with the MEVVA (metal vapor vacuum arc) source implanter at the Key Laboratory of Beam Technology and Material Modification of Ministry of Education, Beijing. Nitrogen ions were implanted at a dose of $2 \times 10^{17} \mathrm{~cm}^{-2}$ under normal ambient temperature, and implantation energies were implanted with three fluences: $60 \mathrm{keV}, 80 \mathrm{keV}$, and $100 \mathrm{keV}$.

2.3. Properties of the Nitrogen Ion-Implanted Layers. To investigate the distribution and range of implanted ions, Monte Carlo simulation program (SRIM-2013 package) was used to make predictions. The density of target AISI M50 steel was set to $7.865 \mathrm{~g} / \mathrm{cm}^{3}$, and the number of total nitrogen ions for calculations was set to 2,000,000. X-ray photoelectron spectroscopy (XPS) analysis was conducted using Thermo Fisher Scientific K-Alpha+ for determining the surface. The microhardness indentations were conducted under the HXS-1000AK hardness tester with a load of $10 \mathrm{~g}$ for $10 \mathrm{~s}$, and each sample was indented at five different locations to calculate average hardness.

2.4. Friction Test and Surface Characterization. Friction and wear were calculated under technically dry friction conditions. A tribological experiment proceeded on a roller-on-flat configuration with the UMT TriboLab device of Bruker Corporation. In this test, AISI M50 steel flat slid against a roller (M50 steel) of $\Phi 12 \times 12 \mathrm{~mm}$ in diameter and a hardness of $710 \mathrm{HV}$. $1 \mathrm{~Hz}$ test oscillating frequency and a constant load of $30 \mathrm{~N}$ were adopted in this test. The track length reached $2.4 \mathrm{~mm}$, and the test lasted for $0.5 \mathrm{~h}$, and each test was repeated three times. Surface chemical state was detected using the DXR ${ }^{\mathrm{TM}}$ Raman spectrometer, with a wavelength of $514.5 \mathrm{~nm}$ laser served as an excitation source, and its power was set to $5 \mathrm{~mW}$. Worn surface morphology was checked using FEI Quanta 250 scanning electron microscopy. The cross section for the wear track was determined by the Contour GT-K surface profiler of Bruker Corporation.

\section{Results and Discussion}

3.1. Distribution of Implanted Ions. The theoretical distribution of implanted ions arising from implantation on sample depth was measured using SRIM software [20]. In comparison with lower energy, higher energy induces the migration of peak nitrogen concentration to the inside of the substrate (Figure 1). The range and depth distribution results of implanted ions are presented in Figure 2. As indicated by the results, the calculated range of implanted nitrogen ions does not exceed $2.0 \mu \mathrm{m}$, and the maximum concentration of the gap can be noted at the depth of around $1.0 \mu \mathrm{m}$. With different implantation energies, the implantation depth increases with energy. According to the LSS theory (Lindhard, Scharff, and Schiott) [21], implantation depth depends on the ions' energy, i.e., the higher the ion energy, the higher the implantation depth. These calculated results are highly consistent with the LSS theory.

Figures 3(a) and 3(b) show the surface N 1s and Cr 2p core spectra in nitrogen ion-implanted samples. According to Figure 3(a), the intense peak near $397.4 \mathrm{eV}$ is ascribed to metal nitrides, such as $\mathrm{Fe}_{\mathrm{x}} \mathrm{N}$. As presented in Figure 3(b), the intense peaks near $583.5 \mathrm{eV}$ and $573.8 \mathrm{eV}$ are possibly caused by the chromium compound. The peak at $574.9 \mathrm{eV}$ stands for the $\mathrm{Cr}_{2} \mathrm{~N}$ phase. This is in good agreement with literature findings [22]. The results of $\mathrm{N} 1 \mathrm{~s}$ and $\mathrm{Cr} 2 \mathrm{p}$ spectra further confirmed the formation of the nitride phase on the surface after nitrogen ion implantation.

3.2. Mechanical Properties. The microhardness in unimplanted samples and nitrogen ion-implanted samples can be seen from Figure 4 . The microhardness of implanted samples under $10 \mathrm{~g}$ load far exceeds that of unimplanted samples. The microhardness in nitrogen ion-implanted samples reduces with the increase of energy. As shown in the family of hardness graphs, the hardness in the unimplanted AISI M50 steel sample is $707 \mathrm{HV}$, and the nitrogen ion-implanted sample $(60 \mathrm{keV})$ shows the maximum hardness of $830 \mathrm{HV}$. In contrast to unimplanted samples, the increase approximately reaches $17 \%$. Nitrogen ion-implanted samples are shown to have a hardness of $920 \mathrm{HV}$. In contrast to unimplanted samples, the increase approximately reaches $30 \%$. The aforementioned hardness-related findings reveal the concurrent increasing trend between hardness and implantation energy of nitrogen ions, indicating that a harder region has formed near the surface. The microhardness results confirm XPS results, confirming element concentration distribution along depth with SRIM. Interstitial nitride phase can effectively strengthen the matrix and improve the hardness.

3.3. Tribological Behavior. Figure 5 presents the friction coefficient curve related to four samples. Obviously, the friction coefficient in unimplanted samples quickly grows to 


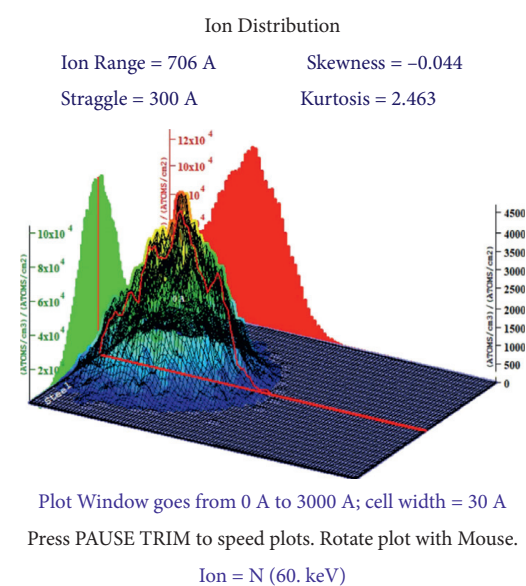

(a)

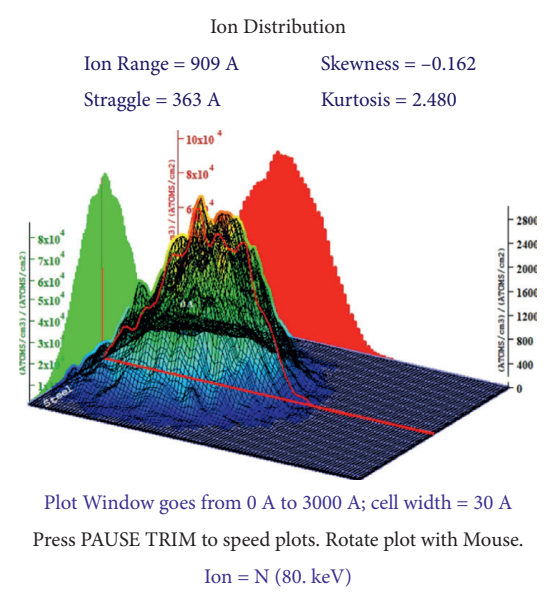

(b)

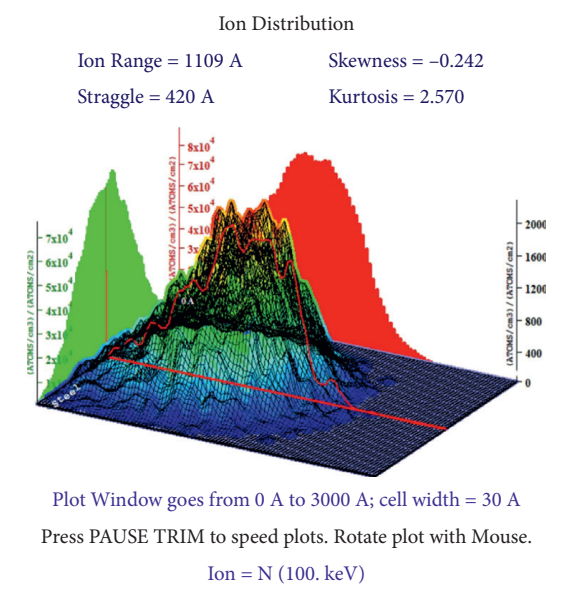

(c)

Figure 1: SRIM software simulations for nitrogen profiles of the implanted sample. (a) $60 \mathrm{keV}$. (b) $80 \mathrm{keV}$. (c) $100 \mathrm{keV}$.

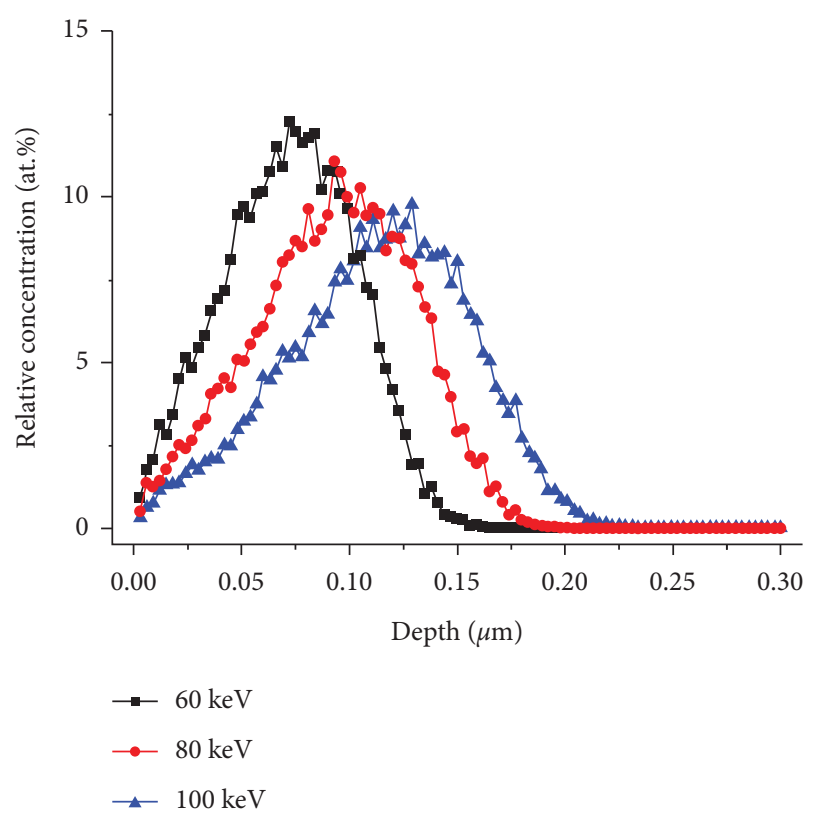

FIGURE 2: Theoretical distribution of implanted nitrogen ions performed at the energy $60 \mathrm{keV}, 80 \mathrm{keV}$, and $100 \mathrm{keV}$ into the AISI M50 steel.

around 0.5 , primarily due to the loss at the surface oxide layer and adsorption layer (Figure 5(a)), whereas the friction coefficient shows a stable trend in the following experimental processes (steady state). It indicates the wide rubbing and poor wear resistance in unimplanted samples. By contrast, in case that nitrogen ion-implanted samples are at $60 \mathrm{keV}$, the friction process will maintain its stability in the first 70 cycles and subsequently deteriorate quickly, indicating that wear life of samples at $60 \mathrm{keV}$ energy is $\sim 70$ cycles. Furthermore, in case that nitrogen ion-implanted samples are at $80 \mathrm{keV}$ energy, a similar friction process can be found, and corresponding sample wear life is 140 cycles. For samples at $100 \mathrm{keV}$ energy, friction coefficient will increase slowly to a similar level, and sample wear life is 320 cycles. The improvement for samples at $100 \mathrm{keV}$ was four times as much as that of samples at $60 \mathrm{keV}$. Interestingly, despite the similarity between unimplanted and implanted samples in the stability friction coefficient, the friction curve at certain stages is not smooth, showing that the impact of implantation and following interactions and relationships with material properties such as wear is rather complicated, and more investigations should be performed. Mean values of the steady state in friction coefficients of the samples are shown in Figure 5(b). The unimplanted sample exhibited high friction coefficients. With nitrogen ion implantation, the samples presented a lower friction coefficient. The mean values of steady friction coefficients of nitrogen ionimplanted samples reduced as energy increased. These results indicate that the wear life in nitrogen ion-implanted samples in the friction experiment is greatly extended.

Wear tracks were examined by the surface profiler (Figure 6) and scanning electron microscopy (Figure 7). The wear depth of the unimplanted sample was obviously deeper than that of the nitrogen ion-implanted samples on worn scars of AISI M50 steel. From the worn surface, there are many grooves and peelings on the surface of unimplanted samples in the sliding direction (Figure $7(\mathrm{a})$ ). The presence of a plastic deformation zone at the bottom suggests the removal of metal partially. For the implanted sample at $60 \mathrm{keV}$, some microgrooves and slight cracking can be observed from worn scars. Meanwhile, plastic deformation is weakened (Figure $7(\mathrm{~b})$ ). For the implanted sample at $60 \mathrm{keV}$, there are few pits and peelings on the worn surface (Figure $7(\mathrm{c})$ ). For the nitrogen ion-implanted sample at $100 \mathrm{keV}$ energy, the wear tracks become smooth (Figure $7(\mathrm{~d})$ ).

Figure 8 demonstrates the cross section of wear track profiles for unimplanted samples, with a large wear depth. Track depth for ion implantation is more irregular. The wear area is remarkably lessened among nitrogen ionimplanted samples. It was further demonstrated that nitrogen ion implantation might effectively alleviate the wear loss on the AISI M50 steel surface. The obtained profiles for 


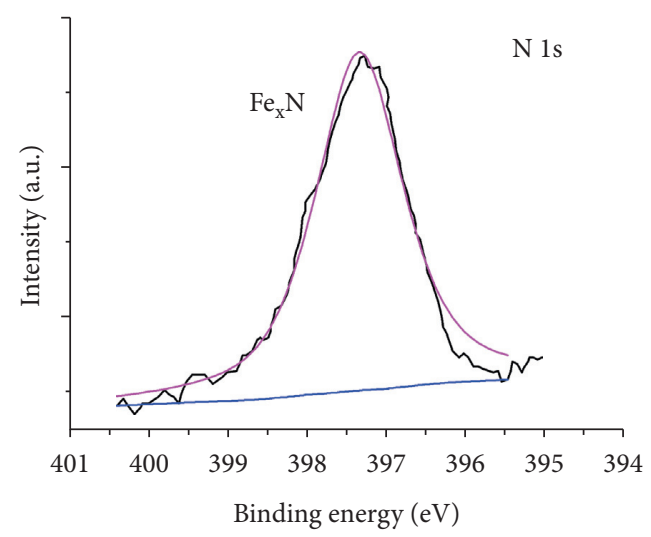

(a)

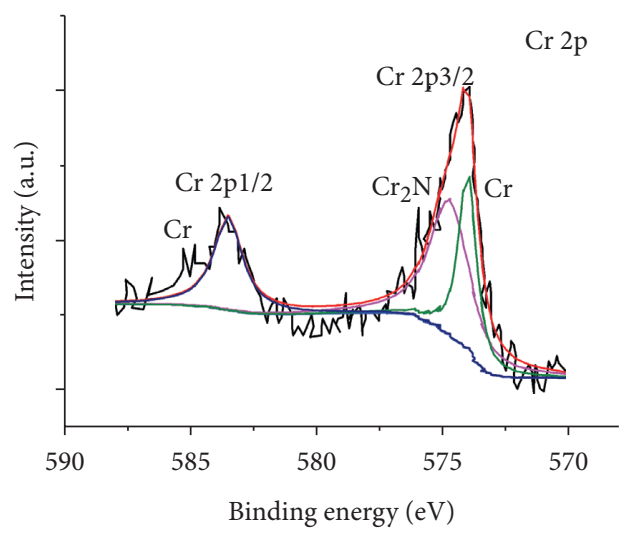

(b)

FIgURE 3: High-resolution XPS spectra of the nitrogen ion-implanted sample. (a) N 1s. (b) Cr 2p.

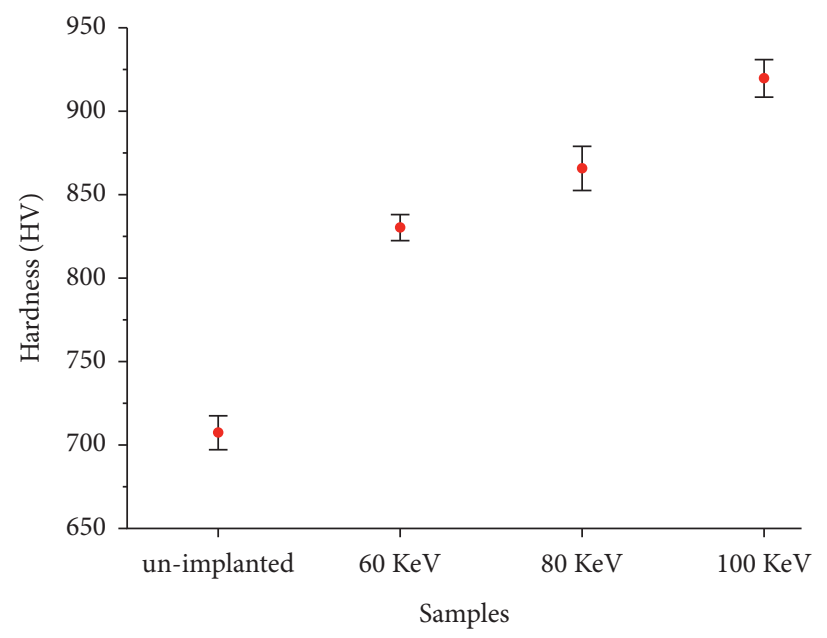

FIgURE 4: Microhardness of samples after nitrogen ion implantation with different energies.

individual sliding tracks fit the microscopic observational results. The wear track shape of unimplanted and nitrogen ion-implanted samples confirms the existence of grooves and wear particles. As is known, material transfer between contacting surfaces will occur during sliding contact, in particular under dry friction conditions. The results show the similarity between unimplanted samples and implanted samples in wear mechanism. A well-known fact is that the steel surface is subject to both adhesive wear and abrasive wear. Adhesive wear arises from the high pressure during individual contact of asperities, which leads to local adhesion, and such contact is later sheared to form junctions [23]. Relative sliding between contact surfaces leads to rupture in the junctions and frequent transfer of material from one surface to the other. As damage increased, adhesion potentially causes scuffing. It can be ascribed to a large increase in friction coefficient. Depending on the simple operating conditions and the elements of the tribosystem, a single wear mechanism possibly plays a dominant role [24]. As mentioned above, adhesion has to be expected as the dominating wear mechanism of those samples. With nitrogen ion implantation, the wear mechanism still belonged to adhesive wear. However, adhesion resistance shows a trend of increase with nitrogen-implanted energy since abrasion resistance will increase when the hardness of wearing material is greater than that in countersamples.

3.4. Raman Spectroscopy of Wear Scars. Raman spectra measurements are made for detecting different phases collected from both unimplanted and implanted AISI M50 steel surfaces after tribological tests. As seen from Figure 9, several oxide phases' features could be seen from the Raman spectra on worn surfaces. They might be attributed to the tribo-caused oxidation on the surface. Some published works suggest that $\alpha-\mathrm{Fe}_{2} \mathrm{O}_{3}$ comes under the R-3c crystal space group, and seven phonon lines may emerge in the Raman spectrum, including two $\mathrm{A}_{1 \mathrm{~g}}$ phonon modes and five $\mathrm{E}_{\mathrm{g}}$ phonon modes $[25,26]$. Peaks at 227 and $494 \mathrm{~cm}^{-1}$ have a connection with the $\mathrm{A}_{1 \mathrm{~g}}$ phonon mode, and peaks at 245, 292, 299, 409, and $609 \mathrm{~cm}^{-1}$ are associated with the $\mathrm{E}_{\mathrm{g}}$ phonon mode. Thus, it can be seen that the wear product is $\alpha-\mathrm{Fe}_{2} \mathrm{O}_{3}$. Comparatively, softer phase for oxides such as 


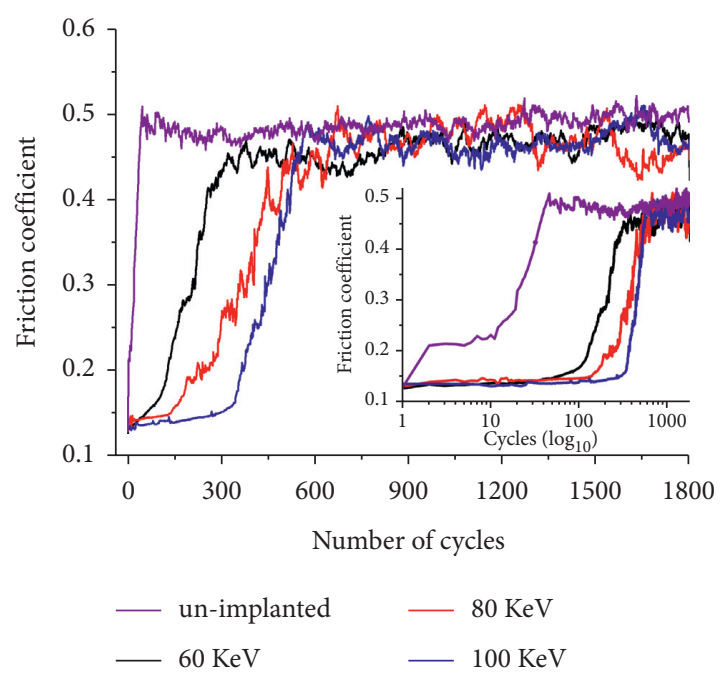

(a)

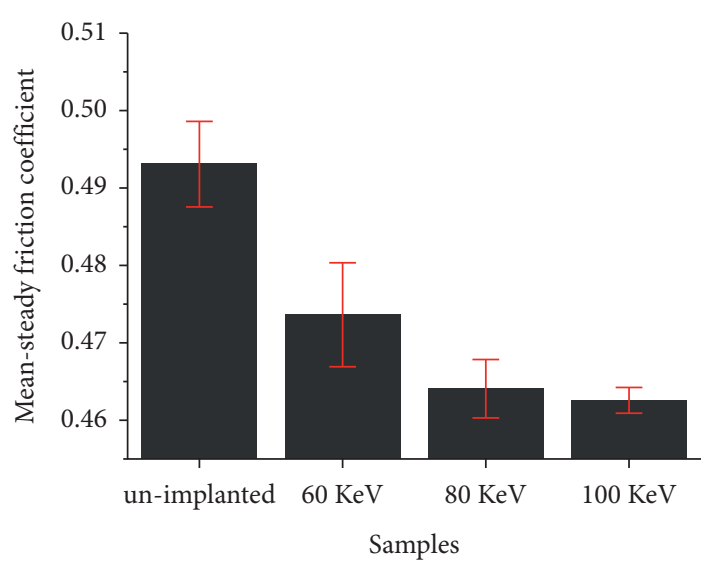

(b)

FIGURE 5: Friction coefficient of unimplanted and nitrogen ion-implanted samples at various energies. (a) The whole test process. (b) Mean values of the steady state.

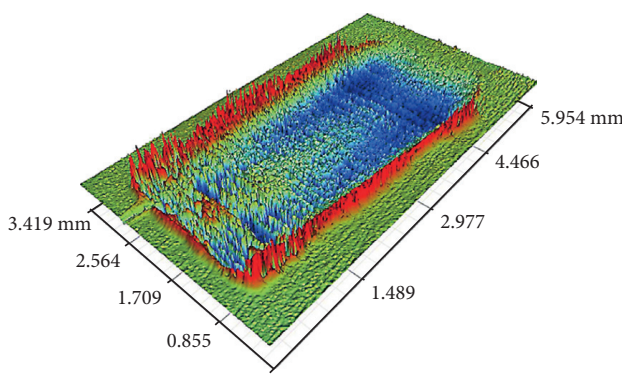

(a)

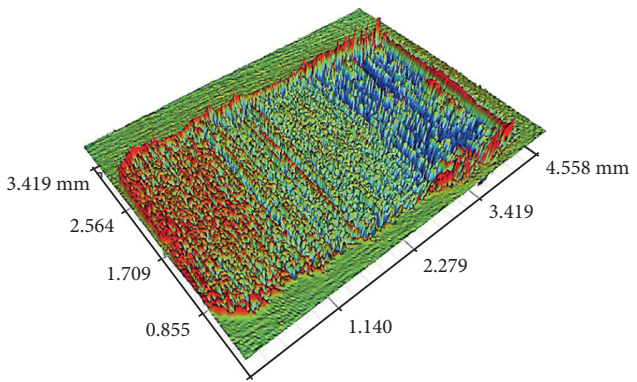

(c)
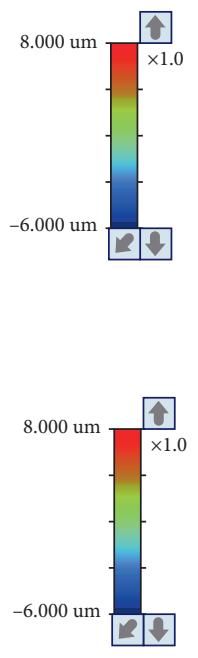

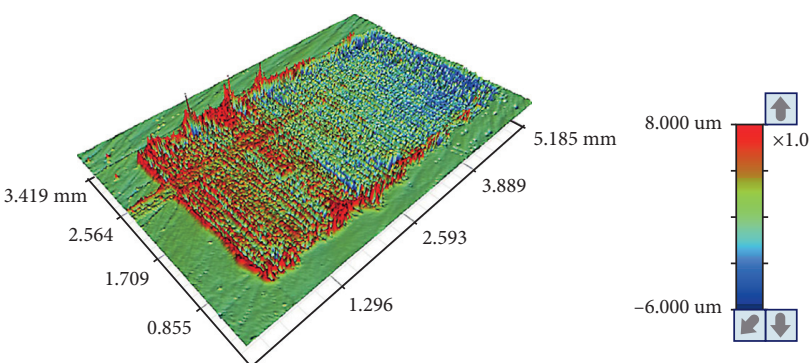

(b)
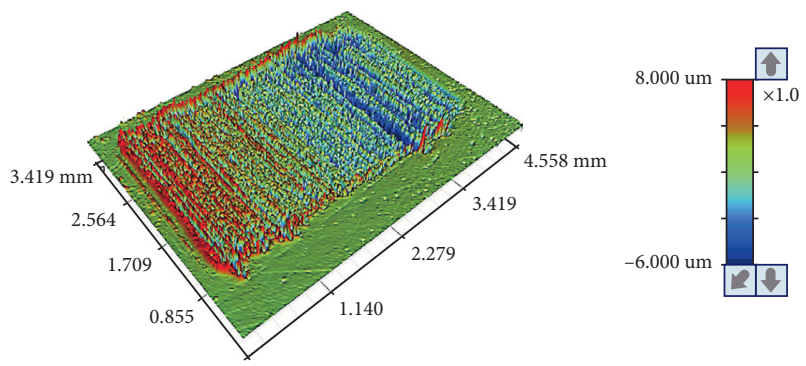

(d)

FiguRE 6: 3D optical profilometer images of the wear tracks for the different implanted energies studied after wear tests. (a) Unimplanted. (b) $60 \mathrm{keV}$. (c) $80 \mathrm{keV}$. (d) $100 \mathrm{keV}$.

$\alpha-\mathrm{Fe}_{2} \mathrm{O}_{3}$ may take shape during initial sliding stages with a low formation temperature. A peak at $680 \mathrm{~cm}^{-1}$ appeared in the Raman spectrum of the implanted sample, indicating the presence of $\mathrm{Fe}_{3} \mathrm{O}_{4}$, and no similar phenomenon could be seen from wear tracks on unimplanted surfaces. Raman bands at $366 \mathrm{~cm}^{-1}$ at a lower nitrogen ion energy belong to the $\alpha-\mathrm{Fe}_{2} \mathrm{~N}$ phase [27].

Lots of scholars indicated that tribo-oxide layers were efficient in decreasing wear, and $\mathrm{Fe}_{3} \mathrm{O}_{4}$ produced more protective layers compared with $\mathrm{Fe}_{2} \mathrm{O}_{3}$ [28]. Oxides $\alpha-\mathrm{Fe}_{2} \mathrm{O}_{3}$ and $\mathrm{Fe}_{3} \mathrm{O}_{4}$ reinforce sliding resistance, which leads to the stability of friction, as seen from Figure 5. Such metallic oxides constitute adhesive bonding between interfaces and thus influence the sliding movement. Therefore, a conclusion can be drawn that nitrogen ion implantation treatment promoted the wear resistance for the substrate. Nitride phases harden the surface and have a low shearing factor, which helps reduce friction and reinforce wear resistance. In the meanwhile, consistent with the expectation, $\alpha-\mathrm{Fe}_{2} \mathrm{O}_{3}$ and $\mathrm{Fe}_{3} \mathrm{O}_{4}$ are formed, and tribological properties in implanted samples are also enhanced. 

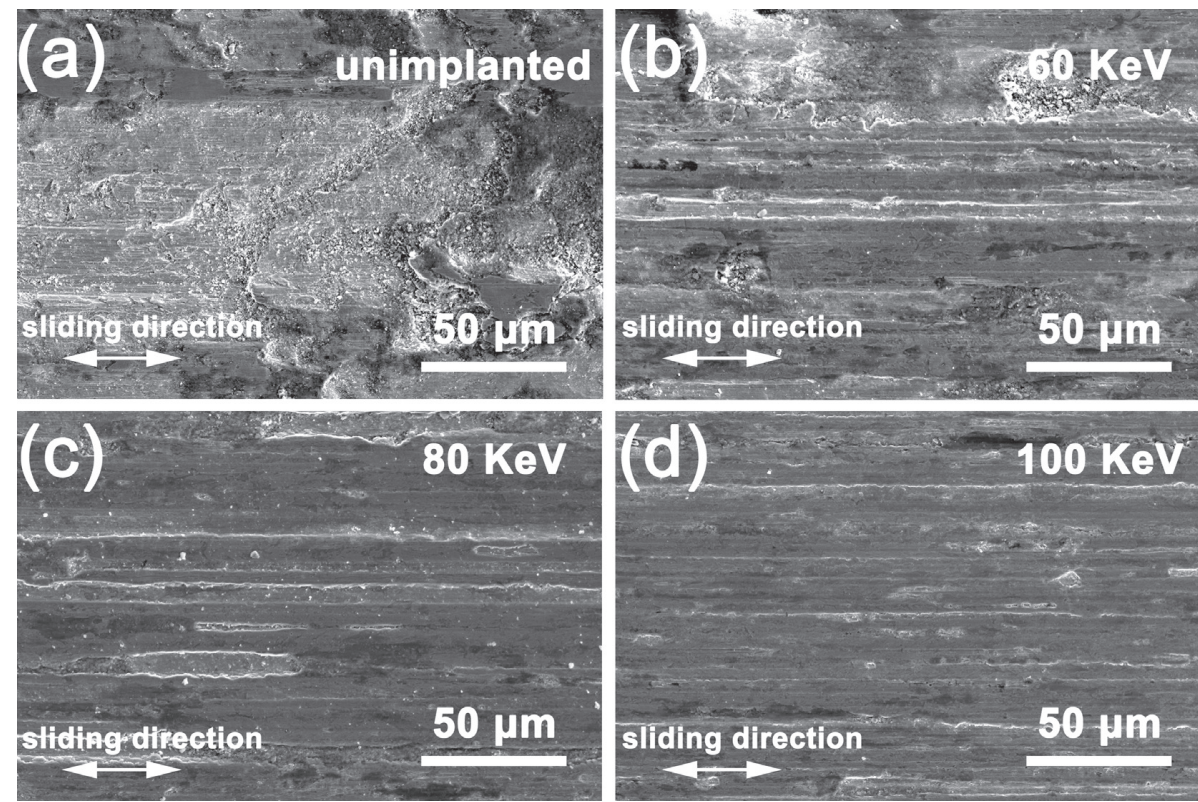

Figure 7: Micromorphologies of worn surfaces. (a) Unimplanted. (b) $60 \mathrm{keV}$. (c) $80 \mathrm{keV}$. (d) $100 \mathrm{keV}$.

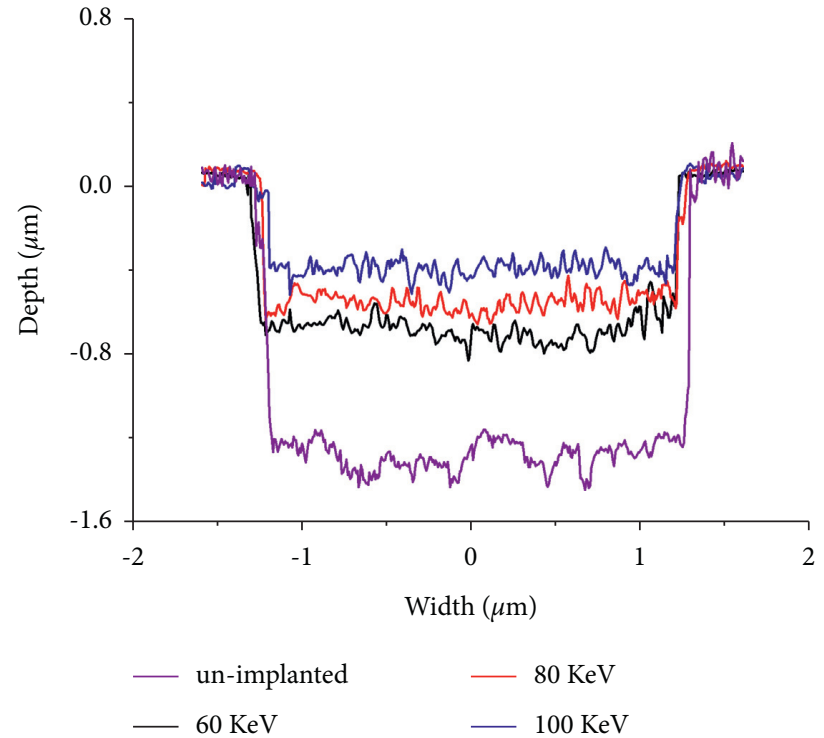

FIgURE 8: Depths of wear scar measured by surface profilometer. (a) Unimplanted. (b) $60 \mathrm{keV}$. (c) $80 \mathrm{keV}$. (d) $100 \mathrm{keV}$.

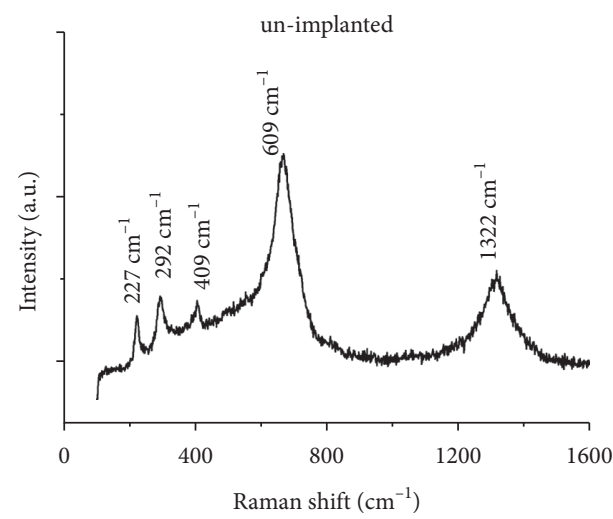

(a)

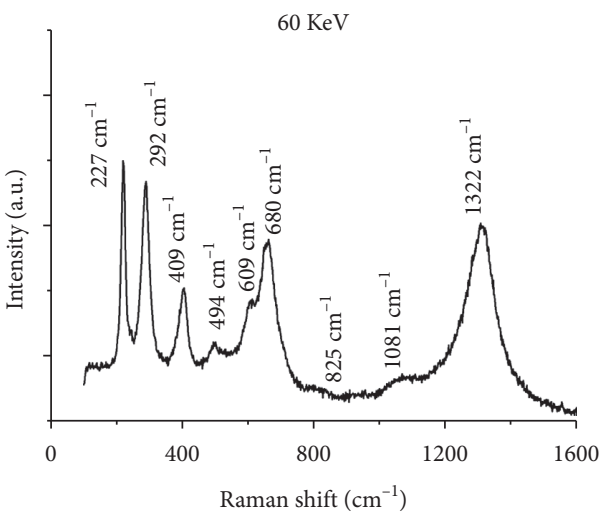

(b)

FIgure 9: Continued. 


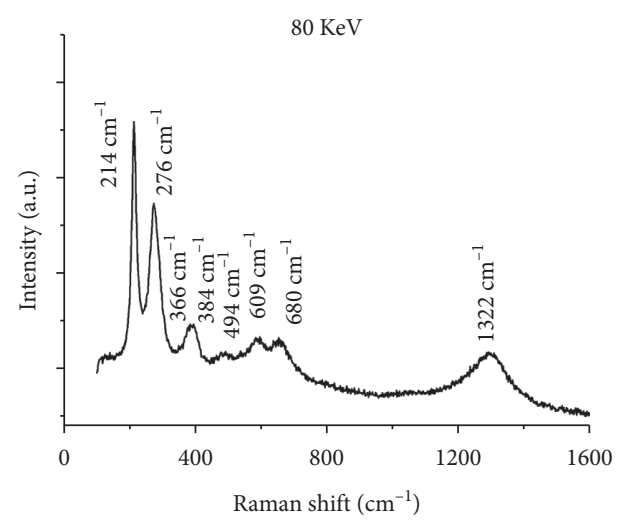

(c)

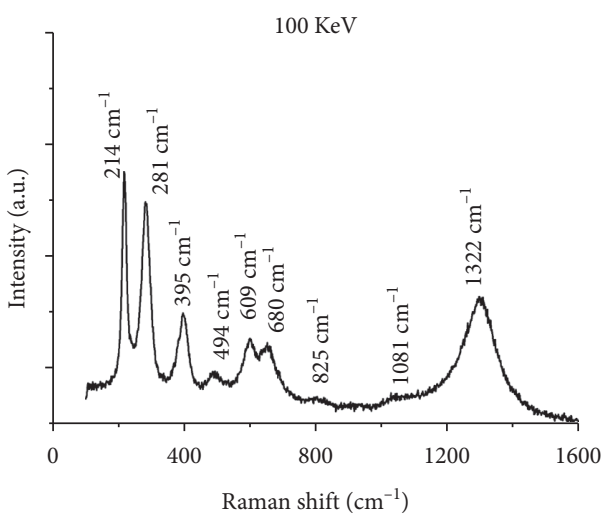

(d)

Figure 9: Raman spectroscopy of surface and wear scars. (a) Unimplanted. (b) $60 \mathrm{keV}$. (c) $80 \mathrm{keV}$. (d) $100 \mathrm{keV}$.

\section{Conclusions}

Nitrogen ion implantation improves AISI M50 steel tribological properties through modifications on the surface layers of the material. As the nitrogen ion-implanted energy increases, both implantation depth and microhardness increase. Material mechanical performance has been significantly improved, and microhardness of the implanted layer at energy $100 \mathrm{keV}$ is 1.3 times greater than that in unimplanted samples. Nitrogen ion implantation at a higher implanted energy can more effectively and efficiently improve wear resistance, and wear life in samples at $100 \mathrm{keV}$ before the steady stage is 4 times greater compared with that in samples at $60 \mathrm{keV}$. It has also been found that oxides $\alpha-\mathrm{Fe}_{2} \mathrm{O}_{3}$ and $\mathrm{Fe}_{3} \mathrm{O}_{4}$ form the adhesive bonding between the interfaces of implanted samples and increase wear resistance. To sum up, the wear mechanism is still mainly adhesive wear upon nitrogen ion implantation, whereas adhesion resistance shows a trend of increase with nitrogenimplanted energy.

\section{Data Availability}

The research data used to support the findings of this study are included within the article.

\section{Conflicts of Interest}

The authors declare that there are no conflicts of interest regarding the publication of this paper.

\section{Authors' Contributions}

Xiangyu Xie and Chao Chen contributed equally to this work.

\section{Acknowledgments}

This research work was supported by the National Natural Science Foundation of China (Grant no. 51605105), the Major Science and Technology Project in Guizhou Province (Grant no. Q.K.H.Z.D.Z.X.Z[2019]3016), the Youth Science and Technology Talents Growth Fund of Education Department of
Guizhou Province (Grant no. KY[2018]300), and special funding of Guiyang Science and Technology Bureau and Guiyang University (Grant no. GYU-KY-[2021]).

\section{References}

[1] H. K. D. H. Bhadeshia, "Steels for bearings," Progress in Materials Science, vol. 57, no. 2, pp. 268-435, 2012.

[2] G. S. Vasyliev and O. M. Kuzmenko, "Pitting suppression of aisi 316 stainless steel plates in conditions of ultrasonic vibration," International Journal of Chemical Engineering, vol. 2020, Article ID 6697227, 7 pages, 2020.

[3] P. Mukhopadhyay, P. S. Kannaki, M. Srinivas, and M. Roy, "Microstructural developments during abrasion of m50 bearing steel," Wear, vol. 315, no. 1-2, pp. 31-37, 2014.

[4] Q. Zhang, J. Luo, X. Y. Xie, J. Xu, and Z. H. Ye, "Experimental study on the skidding damage of a cylindrical roller bearing," Materials, vol. 13, no. 18, 2020.

[5] B. P. Abbott, R. Abbott, and T. D. Abbott, "Observation of gravitational waves from a binary black hole merger," Physical Review Letters, vol. 116, no. 6, 2016.

[6] J. Kusinski, S. Kac, A. Kopia et al., "Laser modification of the materials surface layer-a review paper," Bulletin of the Polish Academy of Sciences, Technical Sciences, vol. 60, no. 4, pp. 711-728, 2012.

[7] D. V. Nazarov, E. G. Zemtsova, A. Y. Solokhin, R. Z. Valiev, and V. M. Smirnov, "Modification of the surface topography and composition of ultrafine and coarse grained titanium by chemical etching," Nanomaterials, vol. 7, no. 1, 2017.

[8] I. Lampé, D. Beke, S. Biri et al., "Investigation of silver nanoparticles on titanium surface created by ion implantation technology," International Journal of Nanomedicine, vol. 14, pp. 4709-4721, 2019.

[9] S. Li, Y. Fan, H. Chen et al., "Manipulating the triboelectric surface charge density of polymers by low-energy helium ion irradiation/implantation," Energy \& Environmental Science, vol. 13, no. 3, pp. 896-907, 2020.

[10] T. R. Rautray, R. Narayanan, and K.-H. Kim, "Ion implantation of titanium based biomaterials," Progress in Materials Science, vol. 56, no. 8, pp. 1137-1177, 2011.

[11] T. R. Rautray, R. Narayanan, T.-Y. Kwon, and K.-H. Kim, "Surface modification of titanium and titanium alloys by ion implantation," Journal of Biomedical Materials Research Part B: Applied Biomaterials, vol. 93B, no. 2, pp. 581-591, 2010. 
[12] Z. Ba, Q. Dong, J. Yin et al., "Surface properties of mg-gd-znzr alloy modified by sn ion implantation," Materials Letters, vol. 190, pp. 90-94, 2017.

[13] P. Vlcak, J. Fojt, Z. Weiss, J. Kopeček, and V. Perina, "The effect of nitrogen saturation on the corrosion behaviour of ti$35 \mathrm{nb}-7 \mathrm{zr}-5$ ta beta titanium alloy nitrided by ion implantation," Surface and Coatings Technology, vol. 358, pp. 144-152, 2019.

[14] F. Wang, C. Zhou, L. Zheng, and H. Zhang, "Improvement of the corrosion and tribological properties of css- 421 aerospace bearing steel using carbon ion implantation," Applied Surface Science, vol. 392, pp. 305-311, 2017.

[15] P. Budzynski, J. Filiks, P. Zukowski, K. Kiszczak, and M. Walczak, "Effect of mixed $\mathrm{n}$ and ar implantation on tribological properties of tool steel," Vacuum, vol. 78, no. 2-4, pp. 685-692, 2005.

[16] M. Szala, D. Chocyk, A. Skic, M. Kamiński, W. Macek, and M. Turek, "Effect of nitrogen ion implantation on the cavitation erosion resistance and cobalt-based solid solution phase transformations of hiped stellite 6," Materials, vol. 14, no. 9, 2021.

[17] S. Verma, P. Dubey, A. W. Selokar, D. K. Dwivedi, and R. Chandra, "Cavitation erosion behavior of nitrogen ion implanted 13cr4ni steel," Transactions of the Indian Institute of Metals, vol. 70, no. 4, pp. 957-965, 2017.

[18] M. Kaminski, P. Budzynski, M. Szala, and M. Turek, "Tribological properties of the stellite 6 cobalt alloy implanted with manganese ions," IOP Conference Series: Materials Science and Engineering, vol. 421, 2018.

[19] P. Budzynski, M. Kaminski, M. Turek, and M. Wiertel, "Impact of nitrogen and manganese ion implantation on the tribological properties of stellite 6 alloy," Wear, vol. 456, 2020.

[20] R. E. Stoller, M. B. Toloczko, G. S. Was, A. G. Certain, S. Dwaraknath, and F. A. Garner, "On the use of srim for computing radiation damage exposure," Nuclear Instruments and Methods in Physics Research Section B: Beam Interactions with Materials and Atoms, vol. 310, pp. 75-80, 2013.

[21] K. Suzuki, "Extended lindhard-scharf-schiott theory for ion implantation profiles expressed with pearson function," Japanese Journal of Applied Physics, vol. 48, no. 4, 2009.

[22] M. Y. Li, E. J. Knystautas, and M. Krishnadev, "Enhanced microhardness of four modern steels following nitrogen ion implantation," Surface and Coatings Technology, vol. 138, no. 2-3, pp. 220-228, 2001.

[23] J. Jin and T. Shao, "Effects of single- and dual-element ion implantation on tribomechanical properties of cronidur 30 bearing steel," Surface and Coatings Technology, vol. 344, pp. 303-311, 2018.

[24] K.-H. Zum Gahr, Microstructure and Wear of Materials, Elsevier, Amsterdam, Netherlands, 1987.

[25] A. Lassoued, B. Dkhil, A. Gadri, and S. Ammar, "Control of the shape and size of iron oxide $(\alpha$-Fe2O3) nanoparticles synthesized through the chemical precipitation method," Results in Physics, vol. 7, pp. 3007-3015, 2017.

[26] Y. Ding, L. Zhang, Q. Liao, G. Zhang, S. Liu, and Y. Zhang, "Electromagnetic wave absorption in reduced graphene oxide functionalized with fe3o4/fe nanorings," Nano Research, vol. 9, no. 7, pp. 2018-2025, 2016.

[27] B. B. Nayak, O. P. N. Kar, D. Behera, and B. K. Mishra, "High temperature nitriding of grey cast iron substrates in arc plasma heated furnace," Surface Engineering, vol. 27, no. 2, pp. 99-107, 2011.

[28] S. Q. Wang, M. X. Wei, F. Wang, X. H. Cui, and C. Dong, "Transition of mild wear to severe wear in oxidative wear of h21 steel,” Tribology Letters, vol. 32, no. 2, pp. 67-72, 2008. 